\title{
Synthesis and Characterization of Waste Eggshell-Based Montmorillonite Clay Catalyst for Biodiesel Production from Waste Cooking Oil
}

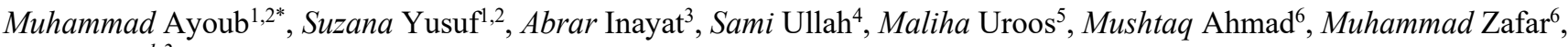 \\ Zulqarnain $^{1,2}$ \\ ${ }^{1}$ Department of Chemical Engineering, University Teknologi PETRONAS, 32610 Seri Iskandar, Perak, Malaysia. \\ ${ }^{2}$ Centre for biofuel and Biochemical Research (CBBR), Institute for Self-sustainable Building, 32610 Seri Iskandar, Perak, Malaysia. \\ ${ }^{3}$ Department of Sustainable and Renewable Energy Engineering, University of Sharjah, 27272 Sharjah, United Arab Emirates. \\ ${ }^{4}$ Department of Chemistry, College of Science, King Khalid University, POB: 9004, Abha, 61413, Saudi Arabia. \\ ${ }^{5}$ Institute of Chemistry, University of the Punjab, 54000 Lahore, Pakistan. \\ ${ }^{6}$ Department of Plant Sciences, Quaid-i-Azam University, Islamabad 45320, Pakistan.
}

\begin{abstract}
The depletion of resources and increase in demand for fossil fuel raise concerns as it is natural and non-renewable. Therefore, it will cause limitation on its availability and continuous reduction. This issue has led to the search for more economic, sustainable, and environmentally friendly alternatives which is biodiesel. The major drawback that reduces the possibility of biodiesel commercialization is the high cost of oil feedstock as it covers $75 \%$ of its total production cost. The waste cooking oil is used as feedstock in continuous transesterification as it is the primary option to lower the cost of biodiesel production. Biodiesel can be prepared using waste cooking oil and catalyst through transesterification reaction. In this research, the focus is on the utilization of chicken and quail waste eggshell to synthesize highly active Calcium Oxide $(\mathrm{CaO})$-based heterogenous catalyst with montmorillonite clay to catalyze efficient conversion of waste cooking oil to biodiesel. The formation of $\mathrm{CaO} /$ montmorillonite catalyst was confirmed based on the outputs from X-ray diffraction (XRD) and Scanning Electron Microscopy (SEM). The physio-chemically characteristics of catalysts exhibited a BET surface area from the ranging from $9.2-9.5 \mathrm{~m}^{2} / \mathrm{g}$ and presence of around $87 \%$ of elemental calcium as constituent through XRF characterization. In addition to this, highperformance liquid chromatography (HPLC) analysis is used to determine the conversion of biodiesel using conventional and microwave heating method which revealed a maximum biodiesel production yield of $98 \%$. This optimum biodiesel yield was obtained at reaction temperature, molar ratio of waste cooking oil to methanol, and catalyst amount of $60^{\circ} \mathrm{C}, 2 \mathrm{~h}, 1: 12,2.5 \mathrm{wt} \%$ and $5 \mathrm{wt} . \%$ for both eggshells, respectively.
\end{abstract}

\section{Introduction}

Increase in demand for renewable resources is increasing every year in line with the raise in human population globally thus, developing environmental concerns resulting from continual dependence on fossil fuel sources [1-3]. The increase in number is a contribution from these sectors including transportation, power generation, industry, and households [4]. Currently, the fossil fuel crisis has globally flounced every region's economy post the decline in global stock of the oil consuming countries around the globe. In regard to that, the rapid depletion of fossil fuels and increase in the number of energy needs has encouraged countries to make savings and conduct studies to obtain renewable fuels [4,5]. Biodiesel is considered to act as a substitute or as an additive to diesel fuel which is nontoxic, renewable, and biodegradable [5-7].

\footnotetext{
* Corresponding author: Muhammad.ayoub@utp.edu.my
}

Biodiesel fuel is considered to be high in cost in comparison to petroleum-based fuel, since $60-80 \%$ of the cost is affiliated with the feed-stock oil, due to the use of expensive, high quality virgin oils such as canola, soybean, sunflower, olive, palm, cottonseed, peanut, and linseed $[8,9]$. The increase in food commodities and improper waste disposal to the environment has made it necessary to use WCO as a biodiesel feedstock $[10,11]$. WCO helps in cost reduction and draws attention since they are renewable and readily available. Certain part of the waste cooking oil is utilized for soap preparation and fodder making, otherwise majority of the WCO are illegally dumped into landfills and other water bodies causing environmental pollution [11]. Typically, biodiesel can be produced using methanol and WCO through transesterification process in the presence of catalyst to produce fatty acid methyl ester (FAME) [4].

Transesterification process takes place using homogeneous acid/alkaline catalyst $[11,12]$ that is 
usually referred as conventional process. Nevertheless, this process has side effects which includes formation of side products such as soap formation [13-15]. Free fatty acids (FFAs) are produced during the cooking of the oil causing the WCO inappropriate for traditional direct base-catalysed transesterification due to soap formation during biodiesel production [7]. Soaps are formed when basic catalyst reacts with FFAs with the feedstock. For alkaline-catalysed transesterification reactions, the oil should not contain more than 1\% FFA. If the level of FFA reaches this volume, soap formation can impede the separation of the ester from the glycerine and also lower the rate of development of ester [14]. Soap production causes gel to form, increases viscosity, and significantly increases the cost of separating the product. A pretreatment process is required to remove the FFAs to achieve high conversion with added cost of production [7]. One method to lower the cost is by using heterogeneous catalyst which helps to avoid the washing steps and further eliminates the wastewater generated.

This study focussed on the development of a solid CaO-based catalyst from two types of eggshells consisting of chicken and quail eggshells for the production of biodiesel using WCO [16]. The purpose of this study is to use $\mathrm{CaO}$ found in the eggshell as a solid catalyst rather than homogenous catalyst that will impact the decreasing cost of biodiesel production, therefore the biodiesel price can be used to compete with the price of diesel oil. Typical eggshell has a low porosity and high content of $\mathrm{CaCO}_{3}$, which is important in the biodiesel industry [17]. The eggshell is combined with activated montmorillonite clay to produce $\mathrm{CaO} /$ montmorillonite catalyst. Calcium carbonate, magnesium carbonate, calcium phosphate, and other organic materials are components of the eggshells. Eggshell offers development opportunities as heterogenous catalysts based on the pore structure and content of $\mathrm{CaCO}_{3}[18-$ $20]$.

The use of this catalyst is expected to provide a solution for obtaining an effective and efficient biodiesel production process feasibility study that reduces environmental pollution. The study was conducted in the laboratory scale which involves several stages, namely catalyst preparation, catalyst characterization, and catalyst testing activity to determine the best operating conditions, including catalyst quantity and heating method. The aim of this research is to observe the comparison between the amount of fatty acid converted to biodiesel by using chicken/montmorillonite catalyst and quail/montmorillonite catalyst.

\section{Materials and Methodology}

\subsection{Materials}

Eggshells were collected from local eateries at Klang, Selangor, Malaysia. Waste cooking oil was procured from local cafeteria around Universiti Teknologi PETRONAS (UTP), Seri Iskandar, Perak. Montmorillonite clay was available at Block 5 laboratory, UTP. The transesterification reaction was performed by using methanol as the alcohol and eggshell ash as heterogenous catalyst. All the solvents and chemicals were requested from UTP Block 4 Chemical Laboratory and directly used without any purification except for WCO. Toluene, potassium hydroxide $(\mathrm{KOH})$, Isopropyl alcohol (2-propanol) and phenolphthalein indicator were used in the titration process to determine acid value. Lastly, n-hexane and isopropanol were used to dilute the biodiesel obtained for conversion and yield analysis.

\subsection{Catalyst preparation}

The chicken and quail eggshell were crushed into small chips separately using a cutting mill and washed thoroughly in tap water to remove any unwanted material adhered on its surface. Then, the crushed eggshells were soaked and rinsed several times with distilled warm water for the removal of excess impurities. The eggshell is then left in a hot air oven at $105{ }^{\circ} \mathrm{C}$ for $24 \mathrm{hrs}$. The dried eggshells were then reduced to small pieces and calcined in a muffle furnace at 900 ${ }^{\circ} \mathrm{C}$ for 4 hours under static air condition.

The activation of montmorillonite clay was done by chemical activation and kept under alkaline condition. The clay was calcined at $800^{\circ} \mathrm{C}$ for 8 hours, then soaked in $0.4 \mathrm{M}$ potassium hydroxide $(\mathrm{KOH})$ solution in $50{ }^{\circ} \mathrm{C}$ for 6 hours. The wet impregnation procedure is used to synthesize both the calcium oxide, $\mathrm{CaO}$ retrieved from the eggshells and clay as a solid catalyst. Therefore, the calcium oxide from both eggshells and the activated clay is mixed together. The catalyst is prepared by $15 \mathrm{mmol}$ $\mathrm{CaO}$ for each 1-gram montmorillonite clay. This mixture was then soaked in $\mathrm{KOH} 0.02 \mathrm{M}$ in $70{ }^{\circ} \mathrm{C}$ for 4 hours, kept for 24 hours, filtered, and dried at $100{ }^{\circ} \mathrm{C}$ for 20 hours, and then calcined for 2 hours at $900{ }^{\circ} \mathrm{C}$ to attain the $\mathrm{CaO} /$ Montmorillonite catalyst.

\subsection{Catalyst characterization}

The properties of the catalyst were assessed as follows: The surface characteristics of the catalyst was obtained by X-ray diffraction (XRD) technique to determine the diffraction lines located at different profile of catalyst. $\mathrm{N}_{2}$ adsorption-desorption isotherms at -196 ${ }^{\circ} \mathrm{C}$ were measured by the static method in an adsorption analyzer (Model: X' Pert3 Powder \& Empyrean, PANalytical). Scanning electron microscope was employed to determine the morphology structure of the element. X-ray fluorescence (XRF) (Model: Bruker; S8 Tiger) gave the elemental composition of the calcined catalyst (eggshell ash). Specific surface areas $\left(\mathrm{S}_{\mathrm{BET}}\right)$ were determined by Brunauer-Emmett-Teller (BET) method using an ASAP 2020 surface area analyzer (Micromeritics). Fourier-transform infrared (FTIR) (Model: Pelkin Elmer, Spectrum One) analysis to identify the crystallinity of sample and provide information on dimensions of unit cell. 


\subsection{Transesterification process}

The WCO that have been collected, was filtered to remove food residues, and then heated at $100-105{ }^{\circ} \mathrm{C}$ for 30 minutes. Transesterification process is conducted in a batch type reactor which consists of three neck glass, equipped with reflux condenser and magnetic hot plate stirrer. Desired amount of catalyst prepared, methanol and WCO is introduced to the reactor and reaction will take place for $65^{\circ} \mathrm{C}$ with range of 1 hour. The reaction mixture is required to be stirred thoroughly at constant speed using magnetic stirrer. Sample is collected after every 30 minutes after the start of the reaction in the batch type reactor for analysis. For the transesterification procedure, the variables that have been constant are the methanol to waste cooking oil ratio which was 12:1.

Besides, the catalyst loading is differed from $2 \%$ and 5\% (wt.\% to the waste cooking oil) for both eggshell catalysts. The similar procedure is repeated for the microwave irradiation process. The conversion of oil to fatty acid methyl esters is analyzed by using a HighPerformance Liquid Chromatography (HPLC). The yield of biodiesel can be calculated by the equation defined below in Equation (1):

Yield of Biodiesel $(\%)=$ (weight of actual biodiesel/ weight of oil used) $\mathrm{x} 100 \%$

The conversion of oil is determined using the following Equation (2):

Conversion $(\%)=($ Weight of Triglycerol - Weight of biodiesel) / (Weight of biodiesel) x 100\%

\subsection{Biodiesel Purification}

The crude biodiesel produced through transesterification process was purified using distilled water. The purification was completed to meet the international standard specification provided by American Society for testing and materials [21]. The biodiesel produced during transesterification if of low value due to the contaminants such as residual methanol, glycerol, catalyst, glycerides and FFA is present [22]. Crude biodiesel was mixed with distilled water and centrifuged at $600 \mathrm{rpm}$ for 5 minutes to avoid formation of emulsion, then slowly extracting the layer of biodiesel without water. The process was repeated twice to ensure colourless wash water is obtained, indicating complete removal of impurities.

\section{Results and Discussion}

\subsection{Catalysts Characterization}

\subsubsection{Catalyst Composition}

Table 1 depicts the chemical composition of chicken/ montmorillonite catalyst and quail/montmorillonite catalyst from the X-ray fluorescence (XRF) analysis. $87.35 \mathrm{wt} \%$ of calcium in addition with phosphorus amount was achieved by quail/clay catalyst since there is traces of phospholipid in the quail eggshell's membrane. Other elements are also traced as tabulated and all of these elements are impurities of the $\mathrm{CaO}$ catalysts. Increase in calcium content improves the quality of biodiesel because $\mathrm{CaO}$ exhibits higher active sites for the reaction to take place.

Table 1 Chemical composition of eggshell/clay catalysts.

\begin{tabular}{|c|c|c|}
\hline \multirow{2}{*}{ Elements } & Chicken/Clay & Quail/Clay \\
\cline { 2 - 3 } & \multicolumn{2}{|c|}{ Concentration (\%) } \\
\hline $\mathrm{Ca}$ & 86.6 & 86.9 \\
\hline $\mathrm{Si}$ & 6.86 & 7.02 \\
\hline $\mathrm{Al}$ & 1.73 & 1.74 \\
\hline $\mathrm{K}$ & 1.54 & 1.48 \\
\hline $\mathrm{Fe}$ & 1.3 & 1.34 \\
\hline $\mathrm{Mg}$ & 0.75 & 0.6 \\
\hline $\mathrm{P}$ & 0.7 & 0.45 \\
\hline
\end{tabular}

\subsubsection{Physical Properties of Catalysts}

Moderate pore diameter ranging from $17 \mathrm{~nm}$ to 20 $\mathrm{nm}$ and surface area within $9 \mathrm{~m}^{2} / \mathrm{g}$ is characterized for both the catalysts which allows reactants to diffuse into the interior of the catalyst as shown in Table 2 [23]. For better diffusion of reactant and product molecules, high pore diameter is desirable. The BET total surface area of $\mathrm{CaO}$ is low under the calcination condition of $800{ }^{\circ} \mathrm{C}$ which is similar to other studies observation at $9 \mathrm{~m}^{2} / \mathrm{g}$ [16]. There are possible differences in the surface area due to the initial particle size of the starting material. Trace pore volume of range $0.03 \mathrm{~cm}^{2} / \mathrm{g}$ to $0.04 \mathrm{~cm}^{2} / \mathrm{g}$ was obtained in agreement with previous study [24]. The total basic strength ( $\mathrm{pH}$ 10.8) for quail/montmorillonite catalyst is recorded and higher than the weakest indicator (pH 9.8) that underwent a colour change. The basic site distribution of $\mathrm{CaO}(135.2 \mu \mathrm{mol} / \mathrm{g})$ showed the presence of good basic strength. The active site of the oxide surface will interact with the methanol proton and contribute to the breakdown of the hydroxide bond, causing the transesterification reaction to initiate the formation of methoxide ion [25]. Such features indicate that the calcined eggshell ash collected have strong catalytic activity. Catalytic activity depends on the specific area of the substrate, base intensity and density of the base site.

Table 2. Physiochemical properties of eggshell catalysts using micromeritics physisorption and chemisorption analyzer.

\begin{tabular}{|l|c|c|}
\hline Properties & $\begin{array}{c}\text { Chicken/Mont- } \\
\text { morillonite catalyst }\end{array}$ & $\begin{array}{c}\text { Quail/Mont- } \\
\text { morillonite catalyst }\end{array}$ \\
\hline $\begin{array}{l}\text { BET surface } \\
\text { area }\left(\mathrm{m}^{2} / \mathrm{g}\right)\end{array}$ & 9.259 & 9.549 \\
\hline $\begin{array}{l}\text { Pore volume } \\
\left(\mathrm{cm}^{2} / \mathrm{g}\right)\end{array}$ & 0.034 & 0.041 \\
\hline $\begin{array}{l}\text { Pore diameter } \\
(\mathrm{nm})\end{array}$ & 17.879 & 20.454 \\
\hline $\begin{array}{l}\text { Basicity } \\
(\mu \mathrm{mol} / \mathrm{g})\end{array}$ & 130.2 & 135.2 \\
\hline $\begin{array}{l}\text { Acidity } \\
(\mu \mathrm{mol} / \mathrm{g})\end{array}$ & 87.4 & 95.03 \\
\hline
\end{tabular}




\begin{tabular}{|l|l|l|}
\hline $\begin{array}{l}\text { Basic } \\
\text { Strength }\left(\mathrm{H} \_\right)\end{array}$ & H_10.2 & H_10.8 \\
\hline
\end{tabular}

\subsubsection{Morphologies of Catalysts}

The scanning electron microscopic image of activated montmorillonite clay and $\mathrm{CaO}$ catalyst is shown in Figure 1 above. For the catalyst, the morphology of $\mathrm{CaO}$ has irregular pores, shapes, and size, varying one surface to another $(30 \mu \mathrm{m}$ of width). The shape of eggshell catalyst was formed by tiny crystals embedded on the large particles, probably due to the heterogenous distribution in the mechanical properties of the eggshell used which can be regarded as an attribute for high catalytic activity [10]. This characteristic heterogeneous morphology of $\mathrm{CaO}$ from calcined eggshell has been noted previously under similar conditions [8].
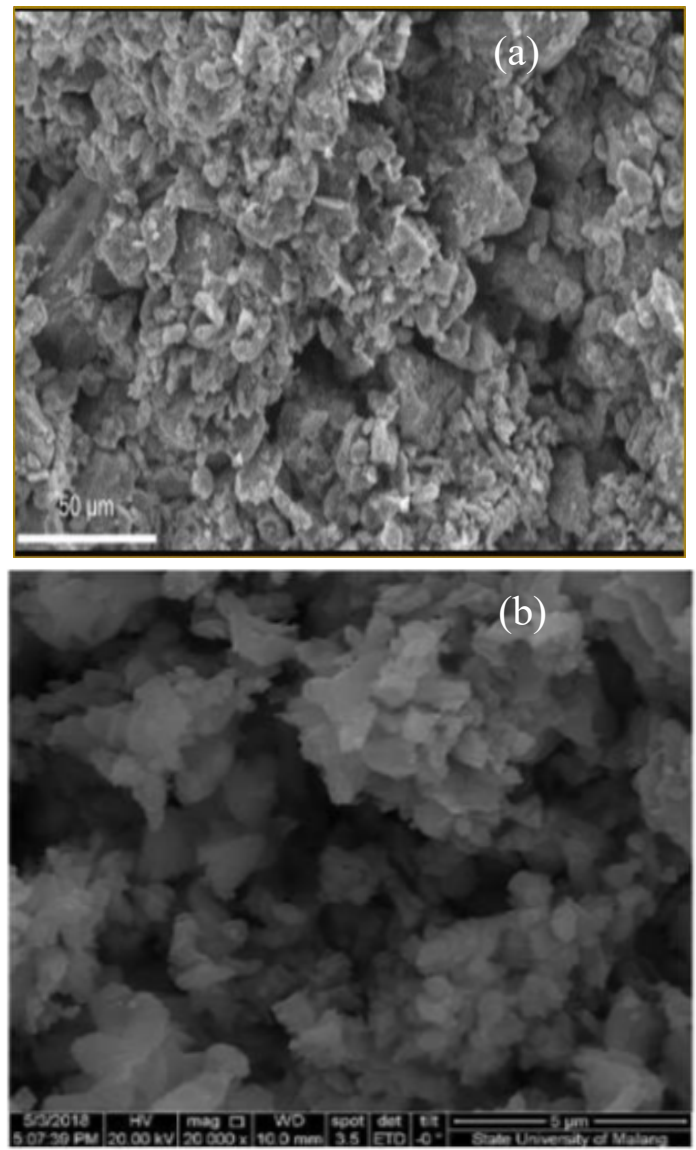

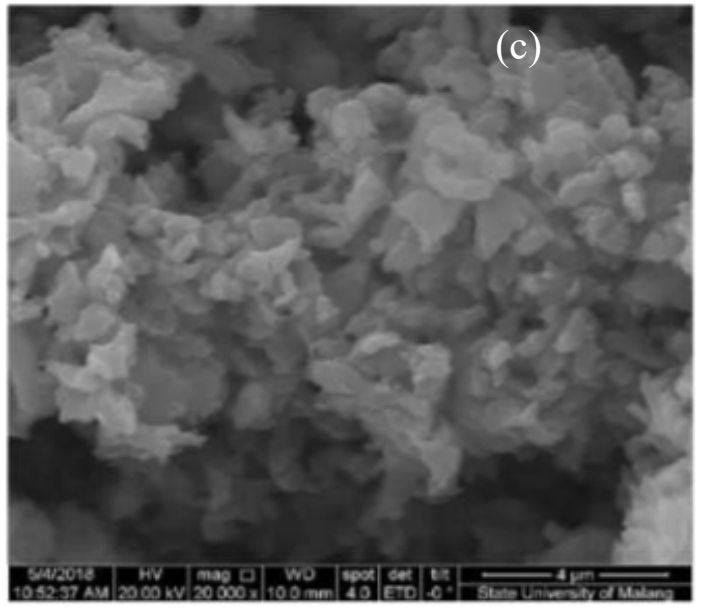

Fig. 1. (a) Morphological form of activated montmorillonite clay, (b) morphological form of chicken/montmorillonite catalyst, (c) morphological form of quail/montmorillonite catalyst.

The scanning electron microscopic image of activated montmorillonite clay and $\mathrm{CaO}$ catalyst is shown in Figure(s) 1,2 and 3 above. For the catalyst, the morphology of $\mathrm{CaO}$ has irregular pores, shapes, and size, varying one surface to another $(30 \mu \mathrm{m}$ of width). The shape of eggshell catalyst was formed by tiny crystals embedded on the large particles, probably due to the heterogenous distribution in the mechanical properties of the eggshell used which can be regarded as an attribute for high catalytic activity [10]. This characteristic heterogeneous morphology of $\mathrm{CaO}$ from calcined eggshell has been noted previously under similar conditions [8].

\subsubsection{Crystalline phases of Catalysts}

Figure 2 shows the XRD patterns for activated montmorillonite clay and the eggshell catalysts. The peaks for activated montmorillonite clay denoted by the blue spectrum appeared at $2 \theta=7.88^{\circ} ; 17.7^{\circ} ; 19.8^{\circ} ; 20.9^{\circ}$ and $27.6^{\circ}$. The peaks have been decreasing after the point $27.6^{\circ}$ as there is a decrease in crystal size which might happened due to the exothermic conditions of the decarbonation process [26].

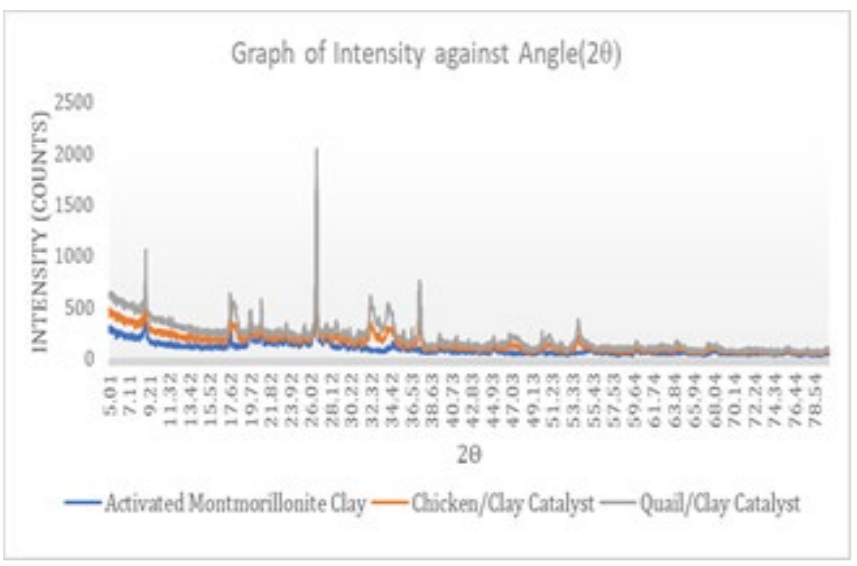

Fig. 2. XRD Spectrum of activated montmorillonite clay and catalyst. 
The peaks in orange spectrum depicts the XRD patterns for chicken eggshell/montmorillonite catalyst which have been synthesized by mixing the $\mathrm{CaO}$ precursor and activated montmorillonite in $\mathrm{KOH}$ solution as explained in the experimental setup. Addition of activated clay into a $\mathrm{CaO}$ compound has the tendency to lower the existing high basicity of $\mathrm{CaO}$ [9]. The peaks appeared at $2 \theta=17.6^{\circ} ; 26.5^{\circ} ; 28.8^{\circ} ; 33.9^{\circ}, 36.6^{\circ}, 37.5^{\circ}$ and $54^{\circ}$. The lower intensity for this catalyst could be due to the minimal production of crystallite size. The grey peaks above shows the XRD patterns for quail eggshell/montmorillonite catalyst and the diffraction lines are locates at $2 \theta=17.8 ; 26.5^{\circ} ; 29.8^{\circ} ; 33.7^{\circ}, 35.6^{\circ}$, $36.5^{\circ}, 46.7^{\circ}, 52^{\circ}$ and $54^{\circ}$. The peaks intensity is slightly higher in comparison with the chicken eggshell/montmorillonite catalyst due to higher crystallization.

\subsubsection{Functional groups of Catalysts}

Figure 3 shows the FTIR spectra for both chicken/montmorillonite clay catalysts. The spectrum of both the catalysts shows the presence of the out-of-plane bending, the asymmetric stretching and the in-plane bending modes of the carbonate groups located at $3642.35 \mathrm{~cm}^{-1}, 993.20 \mathrm{~cm}^{-1}$ and $894.76 \mathrm{~cm}^{-1}$.

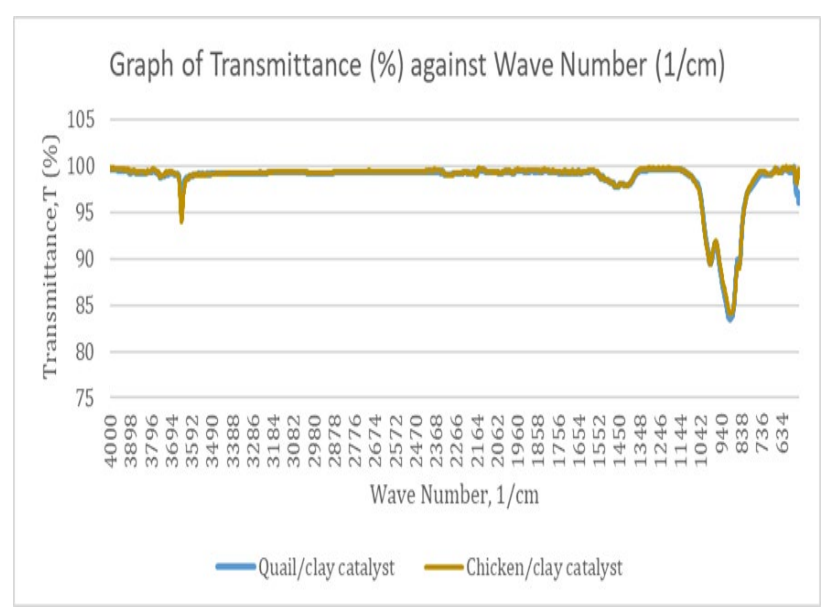

Fig. 3. FTIR spectra of eggshell/clay catalysts.

\subsection{Catalytic Performance}

Figure 4 depicts the conversion obtained for both the type of $\mathrm{CaO} /$ montmorillonite clay catalysts in biodiesel production. Conventional heating method have proven to achieve higher conversion compared to microwave heating in the duration of 2 hours for 2 different values of catalyst loading which is $2 \mathrm{wt} . \%$ and 5 wt.\%. Quail/montmorillonite catalyst have proven to achieve higher conversion compared to chicken/montmorillonite catalyst in all heating methods and catalyst loading. As shown in Figure 6, lower yield for both conventional and microwave heating was obtained with low catalyst loading of $2 \mathrm{wt} \%$, which was insufficient to catalyze the reaction to completion in the formation of methyl ester. Heterogenous catalyst in biodiesel production should range from 3-10 wt.\% for higher yield [6]. Higher biodiesel yield (99\%) was observed at an optimum point of $5 \mathrm{wt} . \%$ catalyst loading as shown in Fig. 4. Reaction rates increases as reactants occupies more catalytic sites until saturation was reached. The impact of mass transfer limitation becomes more significant at higher catalyst loading, thus limiting reactants' accessibility to active sites [12]. The transesterification reaction is strongly dependent on the weight of catalyst which consequently affects the yield. An adequate increase in catalyst concentration results in an increase in the number of its active sites, thereby increasing the yield of methyl ester [16]. Excessive catalyst loading leads to high slurry viscosity and consequent poor reaction mixtures [2].

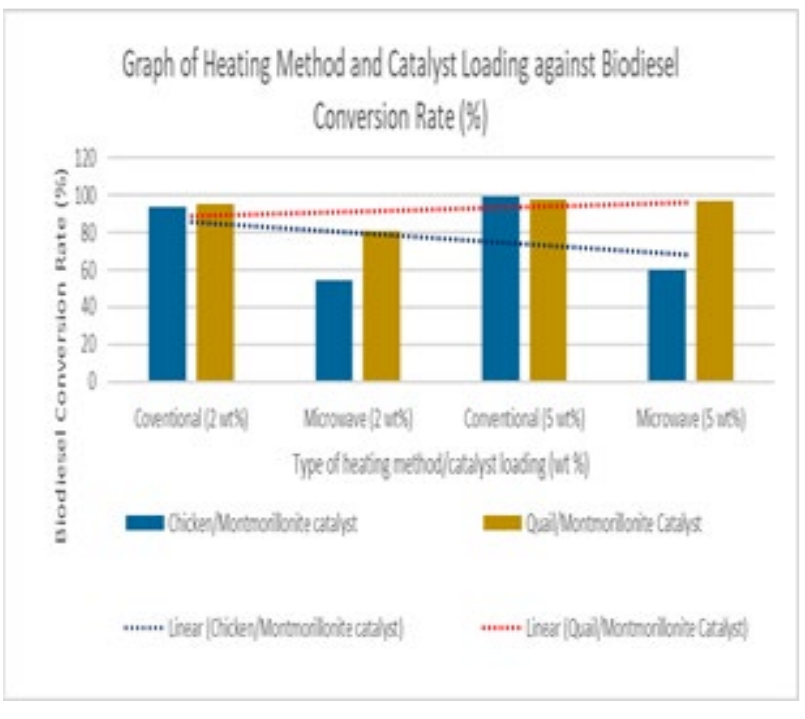

Fig. 4. Heating methods and catalysts activity for Biodiesel production

\section{Conclusion}

Calcium oxide $(\mathrm{CaO})$ solid base catalyst has been successfully prepared from eggshell waste and activated montmorillonite clay. Three factors were investigated oil-to-methanol ratio, catalyst loading and heating method - in order to optimize the process. Optimal reaction conditions obtained were methanol-to-oil molar ratio (12:1), catalyst loading of (5 wt.\%) and temperature $\left(60{ }^{\circ} \mathrm{C}\right)$ using quail eggshell. It was assumed that the catalyst was used in sufficient amount with respect to oil in order to shift the reaction toward the formation of methyl ester. It is proved that the quail eggshell waste catalyst is capable to produce high biodiesel conversion via conventional heating method which is up to $98 \%$. Thus, the study of developing and further engineering $\mathrm{CaO}$ solid base catalyst derived from shell waste still need to be enhanced to improve efficiency of biodiesel production from waste cooking oil.

\section{Acknowledgement}

The author wants to acknowledge Universiti Teknologi PETRONAS YUTP grant (0153AA-E75) and the Ministry of Higher Education (MOHE), Malaysia, to 
support financially under the FRGS grant (0153ABL63). Support from Ministry of Education Malaysia through HICoE award to CBBR is duly acknowledged.

\section{References}

[1] M Ayoub, A Z Abdullah, A Inayat, 2014, Lithium modified Zeolite for conversion of biodiesel-drive glycerol to polyglycerol, Journal of American Institute of Physics 1621 (1), 47-51

[2] M Ayoub, AZ Abdullah, M Ahmad, S Sultana, 2014, Performance of lithium modified Zeolite Y catalyst in solvent-free conversion of glycerol to polyglycerols, Journal of Taibah University for Science 9 (2014) 231235

[3] M Ahmad, MA Ashraf, M Ayoub, M Zafar, S Sultana, 2016, Biodiesel synthesis and characterization using welted thistle plant (Carduus acanthoides) as source of new non-edible seed oil, International Journal of Green Energy 13 (5), 462 - 469

[4] Demirbas, A. Biodiesel production from vegetable oils via catalytic and catalytic supercritical methanol transesterification methods. Prog Energy Combust Sci 31, 466-487. (2005)

[5] M Ayoub, Ah Bhat, S Ullah, M Ahmad, Y Uemura, 2017, Optimization of Biodiesel Production over Alkaline Modified Clay Catalyst, Journal of the Japan Institute of Energy 96 (10), 456-462

[6] Asri, N. P., Podjojono, B., Fujiani, R., \& Nuraini. Utilization of Eggshell Waste as Low-cost Solid Base Catalyst for Biodiesel Production from Used Cooking Oil. IOP Conf Ser Earth Environ Sci 67(1), 012021 (2017).

[7] Ayodeji, A. A., Modupe, O. E., Rasheed, B., \& Ayodele, J. M. Data on $\mathrm{CaO}$ and Eggshell Catalysts Used for Biodiesel Production. Data Brief (2018)

[8] BOZ. Nezahat, \& KARA. Miray. Investigation of the fuel properties of biodiesel produced over an aluminabased solid catal. Turk J Chem 33(3), 433-442 (2009

[9] M Ayoub, S Sufian, S M Hailegiorgis, S Ullah, Y Uemura, 2017, Conversion of glycerol to polyglycerol over waste duck-bones as a catalyst in solvent free etherification process, IOP Conference Series: Materials Science and Engineering 226, 1-8

[10] Ayoub, M., Ullah, S., Inayat, A., Bhat, A. H., \& Hailegiorgis, S. M. Process Optimization for Biodiesel Production from Waste Frying Oil over Montmorillonite Clay K-30. Procedia Eng 148, $742-749$ (2016)

[11] Kamila C. The study of biodiesel production using $\mathrm{CaO}$ as a heterogeneous catalytic reaction. Egypt J Pet 26(2), 341-349. (2017)

[12] Javidialesaadi A., Raeissi S. Biodiesel Production from High Free Fatty Acid-Content Oils: Experimental Investigation of the Pretreatment Step. APCBEE Procedia 5, 474-478 (2001)

[13] Abebe E., Yohannes K. \& Rolando Z. Heterogeneous catalysis for biodiesel production from Jatropha curcas oil (JCO). Energy 36(5), 2693-2700 (2010)
[14] Xiohu F., Rachel B., \& Greg A. Preparation and Characterization of Biodiesel Produced from Recycled Canola Oil. Open Fuel Energ Sci J 2(1),113-118 (2009) [15] Adam L., James B. Heterogeneous catalysis for sustainable biodiesel production via esterification and transesterification. Chem Soc Rev 43, 7887-7916 (2014) [16] Navajas, A., Issariyakul, T., Arzamendi, G., Gandia, L. M., \& Dalai, A. K. Development of Eggshell Derived Catalyst for Transesterification of Used Cooking Oil for Biodiesel Production. Asia-Pac J Chem Eng 8(5), 742748 (2012)

[17] Niju, S., Meera, K. M., Begum, S., \& Anantharaman, N. Modification of Eggshell and its Application in Biodiesel Production. J Saudi Chem Soc 18(5), 702-706 (2014)

[18] Jorge O. \& Merced R. Used Frying Oil for Biodiesel Production Over Kaolinite as Catalyst. Int J Chem Biol Sci 4(1), 35-38 (2011)

[19] AZ Abdullah, Z Gholami, M Ayoub, F Gholami, 2016, Selective Monolaurin Synthesis through Esterification of Glycerol using Sulfated ZirconiaLoaded SBA-15 Catalyst, Chemical Engineering Communications 203, 496 - 504

[20] M Ayoub, S Ullah, A Inayat, SM Mahmood, 2016, Investigation of biodiesel-drive glycerol conversion to polyglycerol over basic modified ALPC catalyst, ARPN Journal of Engineering and Applied Sciences 11 (4), $2668-2672$

[21] Wilson P. Biodiesel production from Jatropha curcas: A review. Renew Sustain Energy Rev 15(5), 2240-2251 (2010)

[22] Atadashi, I.M., Aroua, M.K., Abdul Aziz, A.R. \& Sulaiman, N.M.N. Production of biodiesel using high free fatty acid feedstocks. Renew Sustain Energy Rev 16, 3275-3285 (2012)

[23] Arumugam S., Kien C. \& Paolo F. Catalytic Applications in the Production of Biodiesel from Vegetable Oils. ChemSusChem 2(4), 278-300 (2009)

[24] Le T. \& Kenji O. Catalytic Technologies for Biodiesel Fuel Production and Utilization of Glycerol: A Review. Catalysts 2, 191-222 (2012)

[25] M Ayoub, A Inayat, U Rashid, S Ullah, B Lal, 2015, Synthesis of stable lithium modified mesoporous catalyst for oligomerization of biodisel-drive glycerol to diglycerol, Chemical Engineering Transaction, vol. 45 (2015)

[26] M Ayoub, AZ Abdullah, 2014, Effect of Magnesium Coating Prior to Lithium Loading Over SBA-15 for Stabilization of Its Mesostructure, Advanced Materials Research 917 (2014), 03-09 